IEEE SEST International Conference on Smart Energy Systems and Technologies, Porto, Portugal, Sept. 2019.

This material is posted here with permission of the IEEE. Such permission of the IEEE does not in any way imply IEEE endorsement of any of Group of Energy and Power Electronics, University of Minho, products or services. Internal or personal use of this material is permitted. However, permission to reprint/republish this material for advertising or promotional purposes or for creating new collective works for resale or redistribution must be obtained from the IEEE by writing to pubs-permissions@ieee.org. By choosing to view this document, you agree to all provisions of the copyright laws protecting it.

(C) 2014 IEEE 
Vítor Monteiro, Tiago J. C. Sousa, M. J. Sepúlveda, Carlos Couto, Júlio S. Martins, João L. Afonso, “A Novel Multilevel Converter for On-Grid Interface of Renewable Energy Sources in Smart Grids", IEEE SEST International Conference on Smart Energy Systems and Technologies, Porto, Portugal, Sept. 2019.

\section{A Novel Multilevel Converter for On-Grid Interface of Renewable Energy Sources in Smart Grids}

\author{
Vitor Monteiro \\ Industrial Electronics Department \\ ALGORITMI Research Centre \\ University of Minho \\ Campus de Azurem, Portugal \\ vmonteiro@dei.uminho.pt \\ Carlos Couto \\ Industrial Electronics Department \\ ALGORITMI Research Centre \\ University of Minho \\ Campus de Azurem, Portugal \\ ccouto@dei.uminho.pt
}

\author{
Tiago J. C. Sousa \\ Industrial Electronics Department \\ ALGORITMI Research Centre \\ University of Minho \\ Campus de Azurem, Portugal \\ tsousa@dei.uminho.pt
}

Julio S. Martins

Industrial Electronics Department

ALGORITMI Research Centre

University of Minho

Campus de Azurem, Portugal

jmartins@dei.uminho.pt

\author{
M. J. Sepulveda \\ Industrial Electronics Department \\ ALGORITMI Research Centre \\ University of Minho \\ Campus de Azurem, Portugal \\ mjs@dei.uminho.pt \\ Joao L. Afonso \\ Industrial Electronics Department \\ ALGORITMI Research Centre \\ University of Minho \\ Campus de Azurem, Portugal \\ jla@dei.uminho.pt
}

\begin{abstract}
The on-grid interface of renewable energy sources involves a dc-ac converter for controlling the injected current. In this perspective, a novel topology of grid-tied converter is proposed, assuming as main feature the produced multilevel voltages (five-levels). The proposed grid-tied converter is intended for on-grid interfaces, which is controlled for guaranteeing sinusoidal currents for all grid voltage conditions. The de-side can be linked directly to a dc-to-dc intermediary converter, responsible for interfacing renewable energy sources, as solar photovoltaic or wind power systems. Throughout the paper, a complete examination of the operation principle and the adopted control theory, including current control, as well as hardware project, are comprehensively presented. An accurate computational simulation validation is presented, comprising realistic operating conditions in terms of grid voltage disturbances and operating power. The obtained results prove the advantages of the proposed grid-tied multilevel converter, and establish a comparison with the classical solutions.
\end{abstract}

Keywords-Multilevel Converter; Renewable Energy Sources; Grid-Tied Converter, Power Quality, Smart Grids.

\section{INTRODUCTION}

The emission of greenhouse gases is a global problem, with several targets for the next decades [1]. Basically, these targets are achieved by a more intensive participation of renewable energy sources (RES) (in on-grid or off-grid architectures), through systems that contribute to handle with the inconstant energy production of RES, aiming to balance the relationship between production and consumption [2], and through electric mobility (it can be seen as a system with triple functionalities: energy consumption, energy storage, and injection of energy into the grid) [3]. From the point of view of managing the operation of these three contributions, communication technologies will also play a key role [4]. A contribution for scheduling these resources in a smart grid perspective is presented in [5]. The impacts of RES on the grid vulnerability, particularly from unforeseen wind, is presented in [6]. A particular analysis of the symbiotic collaboration of RES for the smart grids is considered in [7]. A real-time management strategy for the demand-side is proposed in [8] as a contribution for adjusting the operation of controlled electric mobility, ESS, and RES. A unified control for handling RES, from wind power generators, and electric mobility in bidirectional mode, is proposed in [9], where the main idea is to schedule the charging and discharging. In a future perspective of sustainability, RES will be a key technology independently of ESS or electric mobility. Thus, technologies of power electronics converters are necessary for adjusting the voltage levels from the RES to on-grid or off-grid architectures. An interesting review of power converters for RES considering standards, and single-phase and three-phase topologies describing the advantages and limitations of each one, is presented in [10]. A review of power converters focusing on the number of power stages, the decoupling strategy, the questions of using an isolation transformer, and the grid-connected type is presented in [11]. Targeting to enable aspects of flexibility and scalability, the modularity of the power converters is also a key concept, as demonstrated in [12]. Traditionally, for injecting power into the grid (with current feedback) or for off-grid systems (with voltage feedback), fully-controlled full-bridge converters are used. Nevertheless, the increasing advances in power semiconductors and in controlled platforms has contributed decisively for advanced topologies of power converters. Analyzing the requirements for the interface of RES, two distinct structures of power converters can be adopted: (i) A single-stage structure based on a single dc-ac power converter; (ii) A double-stage structure based on dc-to-dc and dc-ac power converters. Both structures have advantages and disadvantages, especially with respect to power levels and the control system, e.g., not all dc-ac topologies can be employed in both structures (e.g., depending on the independent dc-side sources). Based on this contextualization, this paper proposes a novel multilevel (five-level) power converter for on-grid interface of RES. The proposed converter is controlled with current feedback, where it produces a multilevel voltage as a result of the control algorithm, permitting to control the grid-side current. The implemented control only needs to identify the fundamental component of the grid-side voltage in order to obtain a reference current independently of the grid-side voltage problems (e.g., concerning amplitude or harmonic distortion) [13]. Thus, it is easy to comprehend that the quality of the current on the grid-side is directly proportional to the quality of the voltage produced (five-levels). By applying a multilevel converter, it facilitates obtaining a voltage whose harmonic content is mostly based on the fundamental component. With more voltage levels, will result in lower requirements in terms of the filters between the converter and the grid. Based on this principle, it is logical that increasing voltage levels directly implies the 


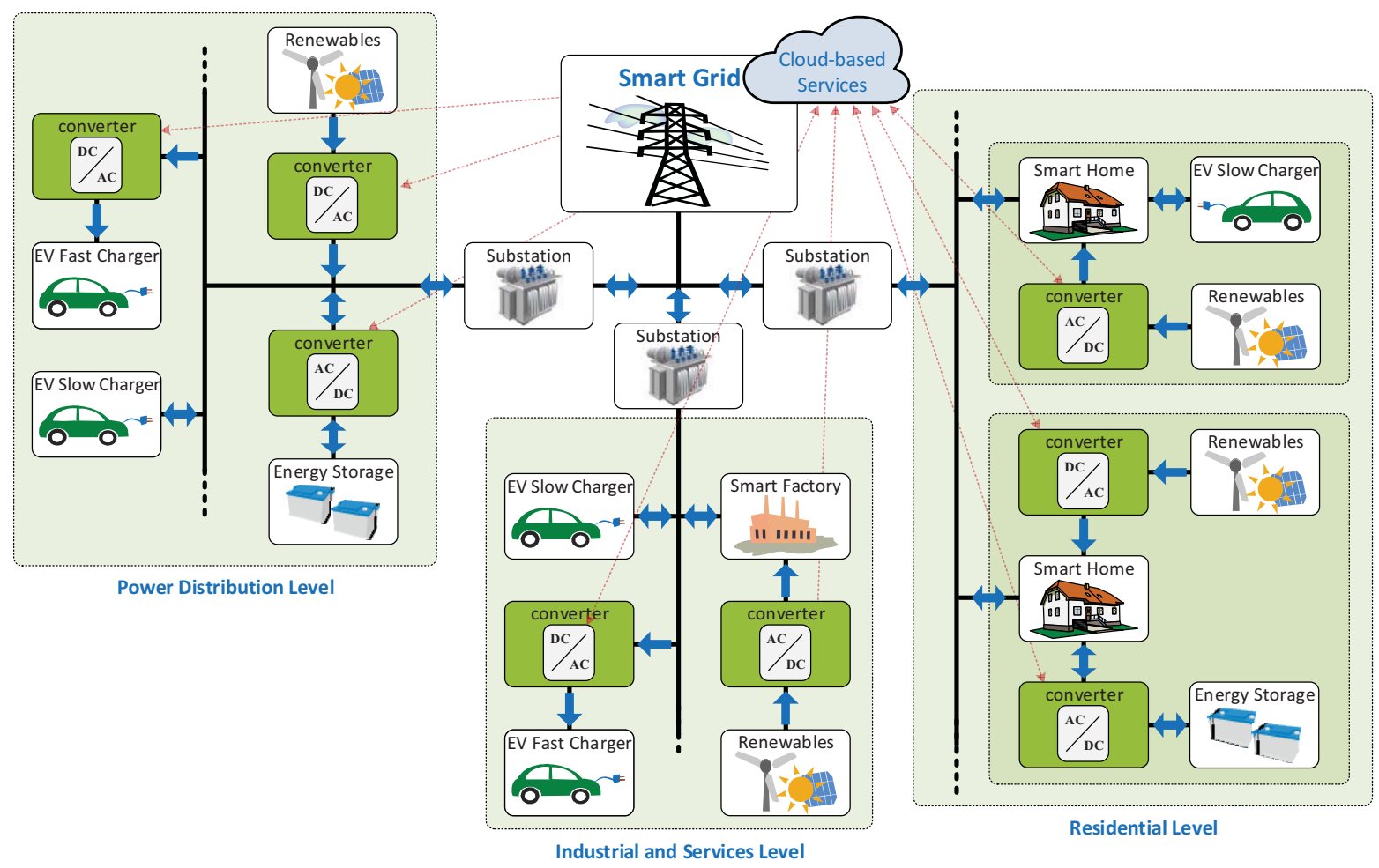

Fig. 1. On-grid power electronics converters in smart grids.

reduction of passive filters, but in practical terms, increasing voltage levels forces hardware complexities and software.

A new topology of five-level converter is proposed in [14], where its structure is based on the Vienna converter. The advantages of a multilevel structure are even more relevant when, on the dc-side, several dc sources are connected to form the dc-link, especially when these sources are connected in series, as can be the case with RES based on photovoltaic (PV) panels [15]. A comprehensive analysis and review of the most fundamental multilevel converters using a reduced number of power semiconductors and the challenges of each structure concerning the application are presented in [16]. Also in this context of multilevel topologies review, a discussion from the point of view of the power theories and applications are presented in [17]. Besides the application at low-voltage levels, it is also important to notice that the multilevel structures are also relevant for medium and high-voltage levels. Reviews of multilevel structures for these cases are offered in [18] and [19]. In [20], a new topology of five levels is proposed, but whose dc-side is formed by two distinct dc-links, limiting the application to the RES interface. The same disadvantage is identified in the nine-level topology proposed in [21]. In [22], [23], and [24] new multilevel topologies are proposed but only operate in unidirectional mode, i.e., receiving power from the grid to dc-link, maintaining the principle of operation of the power factor correction topologies. In [25], [26] and [27], five-level topologies are proposed, but they require more capacitors or more controlled semiconductors, representing the fundamental disadvantage when confronted with the proposal of this paper. Based on this contextualization of multilevel converters, this paper proposes a new five-level topology for RES applications considering an on-grid perspective. In order to establish a contextualization of the proposed topology for smart grids, the capital gains are: (i) Operation as a grid-tied converter, but also allowing operation as an active rectifier, i.e., operation in the four quadrants (cf. section II); (ii) Operation with high levels of power quality, in all quadrants and in all modes of control, with current and voltage feedback (cf. section II); (iii) Structure with a single dc-link, but divided to obtain the five levels (cf. section II); (iv) Better ratio between number of semiconductors and efficiency compared to the topologies of the state of the art (cf. section III.A); (v) Control flexibility to deal with changes in the production of RES (cf. section III.B).

\section{SMART GRIDS:}

\section{A Perspective of POWER CONVERTERs}

Fig. 1 shows the application of power electronics converters for RES and ESS in smart grids. As can be seen, $\mathrm{dc}-\mathrm{ac}$ power electronics converters are required for three levels of the electrical power system in smart grids: Power Distribution Level, Industrial and Services Level, and Residential Level. At the Power Distribution Level, a large scale of RES and ESS can be integrated with the power grid, where its controllability and quality of service is directly performed and guaranteed by distribution system operators or even by transmission system operators toward a demand response control. At the Industrial Level, RES can be integrated in order to reduce the energy consumption from the power grid and to minimize energy costs, where a manager can be performed by distribution system operators. At the Residential Level, RES and ESS can be integrated in a small-scale with the purpose of minimizing the energy costs for the end-user, as well as of contributing to define management strategies for demand response, allowing to establish a distributed scenario of RES. Taking into account the aforementioned three energy levels, the power electronics converters identified in Fig. 1 should be equipped with a communication interface to a cloud-based service. This interface can be used to define the status of the converter (controlled as an on-off electrical appliance), to report power quality problems and to define set-points of operation, as well as to communicate the values about power transactions. 


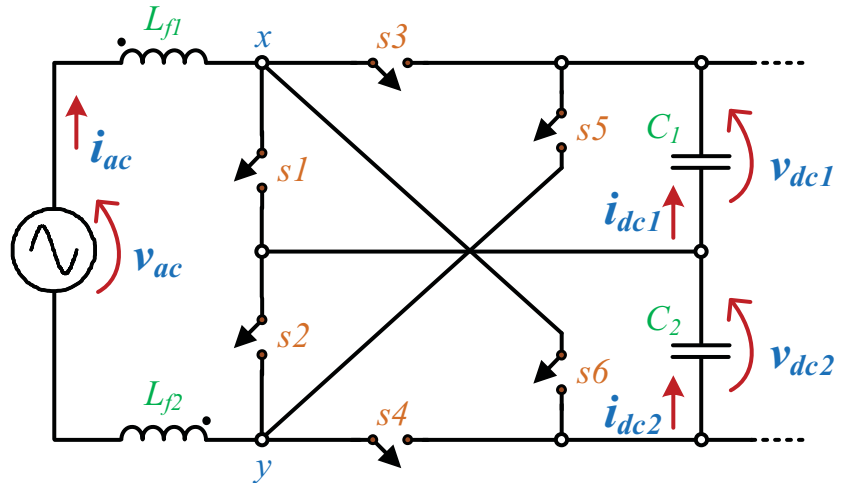

Fig. 2. Topology of the proposed multilevel converter.

\section{TOPOLOGY OF THE PROPOSED \\ Front-END MULTILEVEL CONVERTER}

In Fig. 2 is presented the topology of the proposed converter. Due to the simplicity of analysis and because it is more common for the residential level, a set of PV panels was considered in this paper as an example of RES (where only an additional dc-to-dc converter is necessary between the proposed converter and the PV panels). For example, wind systems could also have been considered, however, an additional ac-to-dc converter would be required besides the dc-to-dc and the dc-ac, since the generator, typically, is based on a three-phase ac electrical machine. Concerning the dc-to-dc, although it is possible to use a simple converter, usually of the boost-type, its control has to be based on an algorithm that allows extracting the maximum power from the RES. As the focus of this paper is on the proposed dc-ac multilevel converter, the analysis of the dc-to-dc converter is discarded, since it does not influence the operation of the proposed converter. It should be noted that the fact of the proposed converter is based on a multilevel structure does not influence the basic operating principle of the whole system (the maximum power extraction is guaranteed by a $\mathrm{dc}-\mathrm{dc}$ converter and it is injected into the grid through a dc-ac converter).

\section{A. Principle of Operation}

The proposed converter consists of 6 switches (bidirectional and bipolar, supporting $v_{d c}$ voltage), a passive $L$ filter (for simplicity of analysis) on the ac-side and a split passive $C$ filter on the dc-side. The dc-link voltage balancing is performed according to the half-cycle of the grid voltage, i.e., during the positive half-cycle a PI controller is responsible for controlling the voltage $v_{d c l}$ and during the negative half-cycle a PI controller is responsible for controlling the voltage $v_{d c 2}$. The main characteristic of the proposed converter is that it can produce different voltage levels, which are obtained by the proper control of each switch. The voltage produced by the converter is obtained between the points $x$ and $y$, represented in Fig. 2, and can assume the values $0,+v_{d c} / 2\left(v_{d c l}\right)$ and $v_{d c}\left(v_{d c l}+v_{d c}\right)$, when the grid voltage is positive, and the values $0,-v_{d c} / 2\left(-v_{d c}\right)$ and $-v_{d c}\left(-v_{d c l}-v_{d c}\right)$, when the grid voltage is negative. This is the main advantage of the proposed converter compared to the traditional solution that employs a full-bridge converter, which only allows the voltages $0,+v_{d c}$ and $-v_{d c}$. The possible states are summarized in Table I. In addition to these states, the proposed converter also allows other states for the switches in order to obtain the same voltage levels. However, if the selection of the state of each switch is not
TABLE I

Selected States of the Proposed DC-AC CONVERTER

\begin{tabular}{|c|c|c|c|c|c|c|c|}
\hline & s1 & $s 2$ & s3 & $s 4$ & $s 5$ & s6 & $v_{x y}$ \\
\hline \multirow{3}{*}{$\begin{array}{l}0 \\
\hat{y} \\
y \\
\partial\end{array}$} & $\mathrm{ON}$ & ON & OFF & OFF & OFF & OFF & 0 \\
\hline & OFF & ON & ON & OFF & OFF & OFF & $v_{d c l}$ \\
\hline & OFF & OFF & ON & $\mathrm{ON}$ & OFF & OFF & $v_{d c} 1+v_{d c 2}$ \\
\hline \multirow{3}{*}{$\begin{array}{l}0 \\
V \\
z \\
z\end{array}$} & OFF & OFF & OFF & OFF & ON & ON & $-v_{d c l} l-v_{d c 2}$ \\
\hline & OFF & $\mathrm{ON}$ & OFF & OFF & OFF & ON & $-v_{d c 2}$ \\
\hline & $\mathrm{ON}$ & $\mathrm{ON}$ & OFF & OFF & OFF & OFF & 0 \\
\hline
\end{tabular}

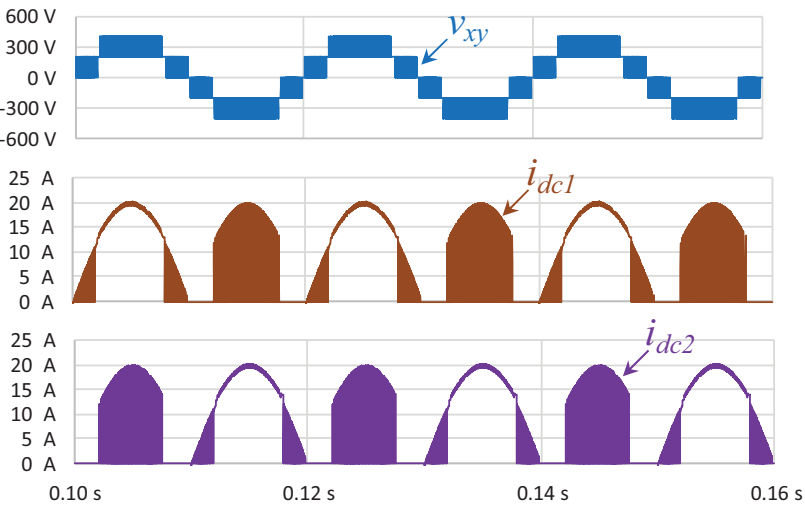

Fig. 3. Validation of the converter considering dc sources in the dc-side: Produced voltage $\left(v_{x y}\right)$; Currents in the dc sources $\left(i_{d c l}, i_{d c 2}\right)$.

properly considered, unbalances in the dc-link capacitors will occur. Based on the states defined in Table I to produce each voltage level, and assuming dc sources directly connected to the dc-link (i.e., without any dc-to-dc converter as interface), Fig. 3 shows the currents $\left(i_{d c l}, i_{d c 2}\right)$ directly measured in each dc source. The current in each source is properly balanced over a cycle of the grid voltage, ensuring that the voltages of the dc-link capacitors can be controlled for the same reference, without unbalances.

\section{B. Proposed Control Structure}

The control structure governing the behavior of the proposed converter is presented in Fig. 4, which is composed of three distinct parts: (i) Voltage regulation on the dc-side (based on proportional-integral (PI) controllers), guaranteeing that both voltages are properly balanced in both half-cycles of the grid voltage; (ii) Definition of the reference current for the ac-side (Fryze-Buchholz-Depenbrock (FBD) power theory), which considers the operating power of the dc-to-dc converter that coincides with the power extracted from the RES; (iii) Current control (finite control set model predictive) that consists in defining the state of the switches in each control cycle. Ignoring the losses in the analysis of the converter, the value of the power on the dc-side (extracted from the RES) is equivalent to the average value of the active power on the ac-side, since it is not used any intermediary energy buffer. Therefore, based on this basic principle of operation, the relation between the power in both sides can be mathematically described as:

$$
\sum_{n=1}^{m} \frac{i_{a c}[n] v_{a c}[n]}{m}-p_{d c}[n]=0,
$$

where $m$ corresponds to 800 based on a grid frequency of $50 \mathrm{~Hz}$ and a sampling frequency of $40 \mathrm{kHz}$, and $P_{d c}[n]$ is the dc-side power calculated at the instant $n$. Since the objective 


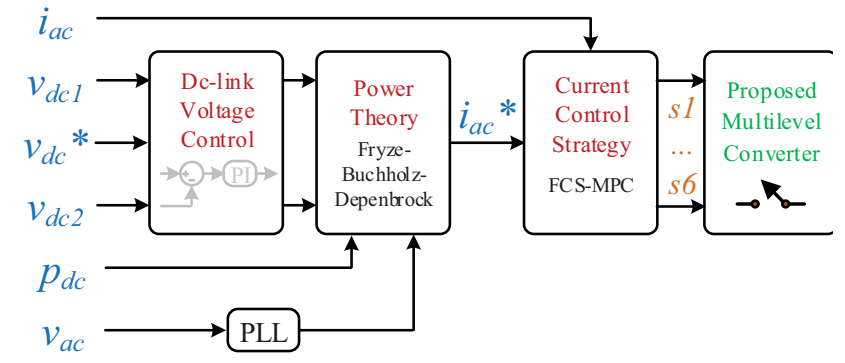

Fig. 4. Control structure for the proposed multilevel converter.

is to control the proposed converter for injecting current, the following relation can be recognized:

$$
\sum_{n=1}^{m} \frac{i_{a c}[n] v_{a c}[n]}{m}-\frac{i_{a c}[n]}{v_{a c}[n]} V_{A C}{ }^{2}[n]=0 .
$$

According to this equation (obtained from equation (1) and substituting $p_{d c}[n]$ according to the FBD power theory, where is considered the ac-side current and volatge), it is possible to guarantee, for all operating powers, that the proposed converter will inject a current with the same waveform of the grid-side voltage, which is acceptable in many situations of on-grid converters, especially when the grid voltage is stable in terms of amplitude, frequency, and harmonic distortion. Establishing a combination of the previous equations in order to put everything as a function of the grid-side current, results in:

$$
i_{a c}[n]=\frac{v_{a c}[n]}{V_{A C}^{2}[n]} p_{d c}[n] .
$$

This equation defines the value of the current on the ac-side (instantaneous value during a control period) for a given operating power on the dc-side, which is based on the instantaneous and rms values of the grid voltage. Analyzing in more detail, it is obvious that the waveform of the current is directly proportional to the waveform of the voltage (with the aforementioned conditions). Assuming a real situation of application, where the grid voltage can have power quality problems, it is important to ensure that the converter only operates with active power (i.e., with zero values of harmonic and reactive power). It is possible to guarantee this situation using, in equation (3), a signal that is proportional to the measured grid voltage, but only containing its fundamental component. This signal is obtained by using an algorithm of phase locked-loop [28], allowing to obtain good results considering the main power quality problems in the power grid, as harmonic distortion, frequency, sags, and swells. According to the control structure that is intended for the proposed converter, the used algorithm allows as input the grid voltage (presenting or not power quality problems) and as output a sinusoidal signal. This strategy allows to obtain a sinusoidal current in the ac-side, being exclusively dependent on the fundamental frequency of the grid and its rms value. Briefly, the obtained signal respects the equation:

$$
v_{a c P L L}[n]=V_{A C} \sqrt{2} \sin [\varnothing]
$$

where $\Phi$ is determined by the phase locked-loop algorithm. Consequently, starting from the equation 3 , the final equation governing the waveform and amplitude of the grid-side current is defined as:

$$
i_{a c}{ }^{*}[n]=\frac{\sqrt{2} \sin [\varnothing]}{V_{A C}[n]} p_{d c}[n] .
$$

In addition to ensuring that the injected current is sinusoidal, this equation allows to define the amplitude of this current, which is directly proportional to the value of power on the dc-side. In this way, for any control cycle, this is the current that should be used as reference for the converter. In other words, in any control cycle, the converter must assume a certain state that corresponds to a produced voltage (one of the five voltages that it can assume) and the ac-side current to follow the reference current. The state that the converter assumes is defined by a finite control set model predictive control. This strategy is based on the mathematical analysis of the circuit with the intent to predict the ac-side current as a controlled function of its actual and previous values. As it is not the purpose of this paper to detail the current control strategy, but to show that the proposed converter operates as expected, the current control strategy is briefly presented as follows. As a consequence of the analysis in terms of the voltages and the currents on the ac-side, the following equation is defined:

$$
\frac{d i_{a c}(t)}{d t}=L^{-1}\left(v_{a c}(t)-v_{x y}(t)\right),
$$

As shown in Fig. 2, $v_{x y}$ denotes the voltage assumed by the converter. Since this is a differential equation, a discretization process was used based on the forward Euler method, resulting in:

$$
i_{a c}[n+1]=T L^{-1}\left(v_{a c}[n]-v_{x y}[n]\right)+i_{a c}[n] .
$$

With this ac-side current $\left(i_{a c}[n+1]\right)$ and the reference current defined by the equation (5), a simple cost function is used:

$$
g[n+1]=\left\|i_{a c}{ }^{*}[n+1]-i_{a c}[n+1]\right\|^{2},
$$

where the reference of current in $n+1$ is extrapolated as:

$$
\begin{gathered}
i_{a c}{ }^{*}[n+1]=4 i_{a c}{ }^{*}[n]-6 i_{a c}{ }^{*}[n-1]+4 i_{a c}{ }^{*}[n-2] \\
-i_{a c}{ }^{*}[n-3] .
\end{gathered}
$$

Posteriorly, the state of the converter is defined for minimizing the error according with the result of the cost function.

\section{VALIDATION}

In this section, a set of validations are presented using the software PSIM and considering a dc-link voltage of $400 \mathrm{~V}$, i.e., $200 \mathrm{~V}$ in each capacitor. Fig. 5 presents a result that validates the correct operation of the proposed converter as a whole, since it shows the three main characteristics properly controlled: (i) The levels that the converter can assume (five levels); (ii) The sinusoidal current on the ac-side; (iii) The controlled voltages on the dc-side-for both capacitors. In addition to these obvious characteristics, it is also possible to verify two distinct cases with respect to the grid voltage. In case \#1, a sinusoidal grid voltage was considered, without any type of undesired characteristic. On the other hand, in case \#2, it was considered a grid voltage that presents harmonic distortion, whose value is about $3 \%$. This result of case \#2 was considered to verify that, from the point of view of the proposed converter, there is no change in its operation 


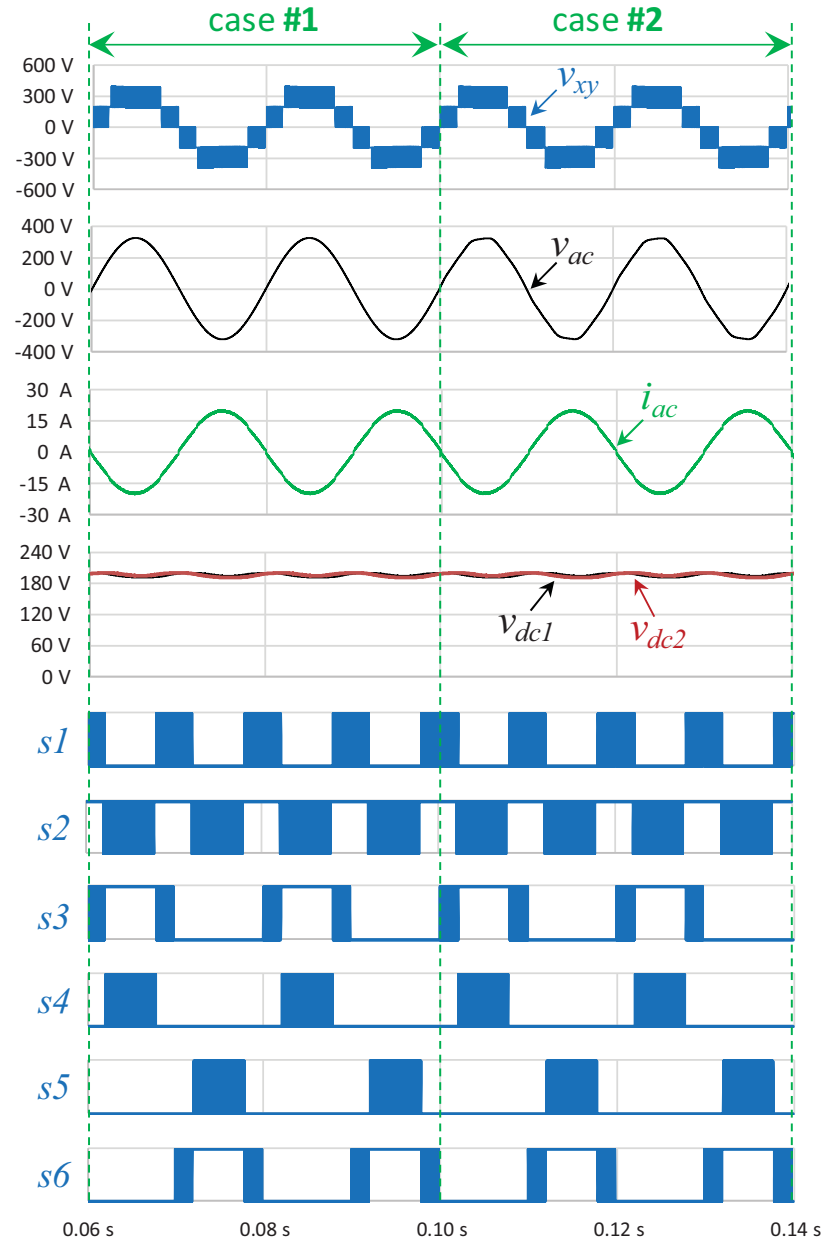

Fig. 5. Validation in steady-state of the produced voltage $\left(v_{x y}\right)$, grid-side voltage $\left(v_{a c}\right)$, grid-side current $\left(i_{a c}\right)$, dc-side voltages in both capacitors $\left(v_{d c l}, v_{d c}\right)$, considering two situations: Case \#1 - with a sinusoidal grid-side voltage; Case \#2 - with a distorted grid-side voltage.

and that, in both cases, the current at the ac-side is sinusoidal (with a value of THD of $2.3 \%$ ).

In Fig. 6 is presented a result that validates the proposed converter in transient-state. For this, a variation of $50 \%$ in operating power was considered. Initially, it was considered a $50 \%$ decrease and, later, an increase of $50 \%$. These situations were considered as critical for the operation of the converter. Under normal operating conditions, with a RES interface, such abrupt variations in the operating power hardly occurred. Typically, operation changes occur with a smoother transition. Still in Fig. 6, the current of the converter is highlighted compared to its reference. As it turns out, the converter is properly controlled (voltage levels produced), allowing the current (control feedback) on the ac-side to follow its reference. Although the current control is not the focus of this paper, it is verified that for the sudden change of $50 \%$, the controlled current reaches its reference in just less than $0.2 \mathrm{~ms}$. In this figure, it is also verified that the voltages assumed by the converter do not suffer significant variations, regardless of the variations in the reference current (which are originated due to the change in operating power). Following the same line of reasoning, in Fig. 7 is presented a result that allows verifying in detail the simultaneous crossing by zero of the produced voltage $\left(v_{x y}\right)$ and grid-side current $\left(i_{a c}\right)$, although they are in phase opposition. The proposed converter was compared with the traditional solution based on the fully-controlled full-bridge
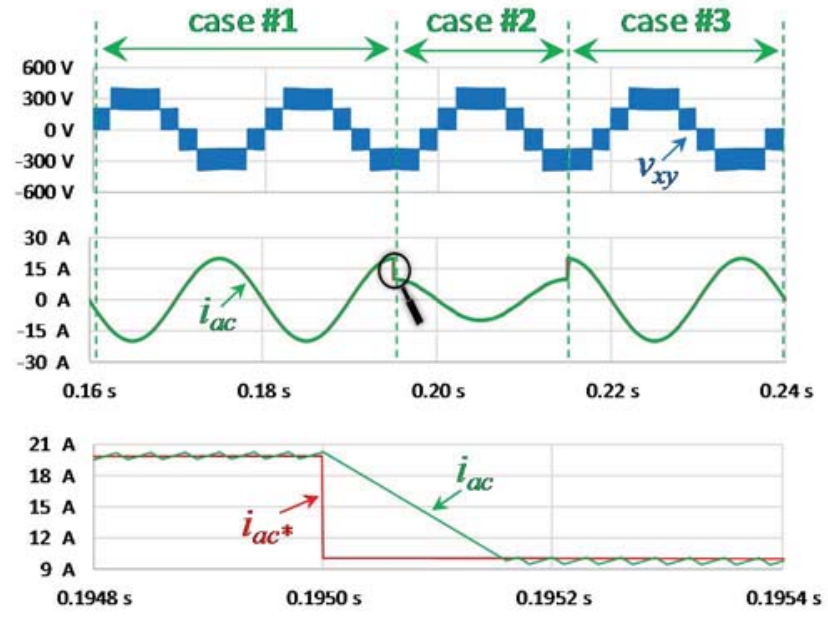

Fig. 6. Validation in transient-state of the produced voltage $\left(v_{x y}\right)$ and the grid-side current $\left(i_{a c}\right)$, considering two sudden situations: Transition from case \#1 to case \#2 decreasing the power in $50 \%$; Transition from case \#2 to case \#3 increasing the power in $50 \%$.

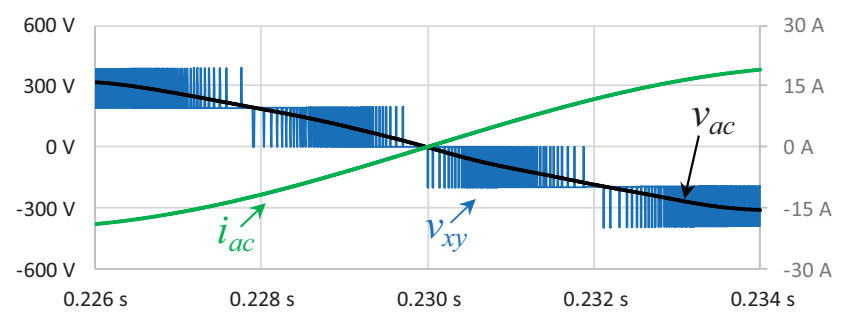

Fig. 7. Validation in steady-state of the produced voltage $\left(v_{x y}\right)$, the grid-side voltage $\left(v_{a c}\right)$ and the grid-side current $\left(i_{a c}\right)$ when crossing by zero.
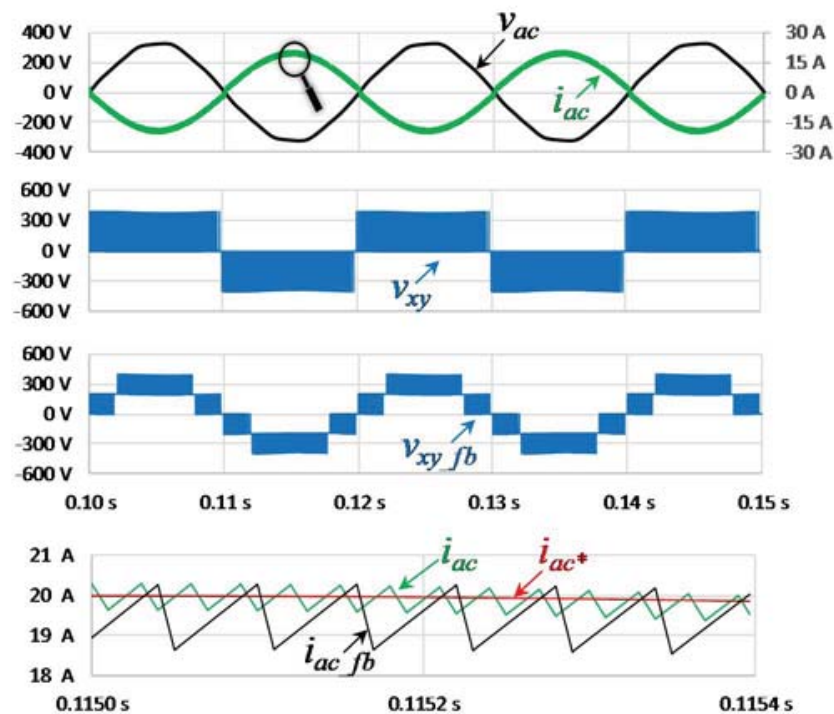

Fig. 8. Validation of the proposed converter when compared with the traditional solution based on the full-bridge full-controlled converter: Grid-side voltage $\left(v_{a c}\right)$; Produced voltage $\left(\mathrm{v}_{\mathrm{xy}}, v_{x y} f b\right)$; Grid-side currents $\left(i_{a c}, i_{a c f b}\right)$; Grid-side reference current $\left(i_{a c}{ }^{*}\right)$.

converter. The results obtained are presented in Fig. 8, where it is possible to verify the voltage produced by each of the converters and the current on the grid-side. In this figure, it is also possible to verify in detail the current on the grid-side when compared to the reference current. As shown, the current of the proposed converter $\left(i_{a c}\right)$ has a much lower ripple value than the current of the fully-controlled full-bridge converter $\left(i_{a c} f b\right)$, despite the characteristics of the model being the same. This situation is due to the fact that 
the proposed converter operates with five voltage levels instead of the three levels of the traditional solution.

\section{CONCLUSIONS}

The on-grid interface of renewable energy sources (RES) requires the use of controlled power converters. In this sense, this paper proposes a novel dc-ac power converter that allows controlling the injected current into the ac power grid, being able to operate with five voltage levels, but with a reduced number of switches, this being its main advantage. The operation principle of the proposed power converter is presented throughout the paper, as well as a description of the adopted control system. The proposed topology was validated considering different operating conditions, namely in steady-state and transient-state, as well as for the most relevant ac grid voltage conditions. The obtained results allow to validate the proposed topology, highlighting the advantages when compared with the more conventional solutions.

\section{ACKNOWLEDGMENT}

This work has been supported by FCT - Fundação para a Ciência e Tecnologia within the Project Scope: UID/CEC/00319/2019. This work has been supported by FCT Project newERA4GRIDs PTDC/EEI-EEE/30283/2017, and by the FCT Project DAIPESEV PTDC/EEIEEE/30382/2017. Tiago Sousa is supported by the doctoral scholarship SFRH/BD/134353/2017 granted by FCT.

\section{REFERENCES}

[1] Bimal K. Bose, "Global Warming - Energy, Environmental Pollution, and the Impact of Power Electronics," IEEE Ind. Electron. Mag., vol.4, no.1, pp.6-17, Mar. 2010.

[2] Marc Beaudin, Hamidreza Zareipour, Anthony Schellenberglabe, William Rosehart, "Energy storage for mitigating the variability of renewable electricity sources: An updated review," Journal of Energy for Sustainable Development, Elsevier, vol.14, no.4, pp.302314, Dec. 2010.

[3] Vítor Monteiro, J. G. Pinto, João L. Afonso, "Operation Modes for the Electric Vehicle in Smart Grids and Smart Homes: Present and Proposed Modes," IEEE Trans. Veh. Tech., vol.65, no.3, pp.10071020, Mar. 2016.

[4] João C. Ferreira, Vitor Monteiro, João L. Afonso, "Vehicle-toAnything Application (V2Anything App) for Electric Vehicles," IEEE Trans. Ind. Informat., vol.10, no.3, pp.1927-1937, Aug. 2014.

[5] Ahmed Yousuf Saber, Ganesh Kumar Venayagamoorthy, "Resource Scheduling Under Uncertainty in a Smart Grid with Renewables and Plug-in Vehicles,” IEEE Syst. J., vol.6, no.1, pp.103-109, Mar. 2012.

[6] Mir Hadi Athari , Zhifang Wang, "Impacts ofWind Power Uncertainty on Grid Vulnerability to Cascading Overload Failures," IEEE Trans. Sustain. Energy, vol.9, no.1, pp.128-137, Jan. 2018.

[7] Frede Blaabjerg, Josep M. Guerrero, "Smart Grid and Renewable Energy Systems," ICEMS International Conference on Electrical Machines and Systems, pp.1-10, Aug. 2011.

[8] Mosaddek Hossain Kamal Tushar, AdelW. Zeineddine, Chadi Assi, "Demand-Side Management by Regulating Charging and Discharging of the EV, ESS, and Utilizing Renewable Energy," IEEE Trans. Ind. Informat., vol.14, no.1, pp.117-126, Jan. 2018.

[9] Shuang Gao, K. T. Chau, Chunhua Liu, Diyun Wu, C. C. Chan, "Integrated Energy Management of Plug-in Electric Vehicles in Power Grid With Renewables,” IEEE Trans. Veh. Technol., vol.63, no.7, pp.3019-3027, Sept. 2014.

[10] Soham Deshpande, N. R. Bhasme, "A Review of Topologies of Inverter for Grid Connected PV Systems," IEEE i-PACT Innovations in Power and Advanced Computing Technologies, pp.16, Apr. 2017.

[11] Soeren Baekhoej Kjaer, John K. Pedersen, Frede Blaabjerg, "A Review of Single-Phase Grid-Connected Inverters for Photovoltaic
Modules," IEEE Trans. Ind. Appl., vol.41, no.5, pp.1292-1306, Oct. 2005.

[12] Pavel Purgat, Jelena Gerber-Popovic, Pavol Bauer, "Modularity in Power Electronics: Conceptualization, Classification and Outlook," IEEE IECON Industrial Electronics Conference, pp.1307-1312, Beijing China, Nov. 2017.

[13] An Luo, Qianming Xu, Fujun Ma, Yandong Chen, "Overview of Power Quality Analysis and Control Technology for the Smart Grid," SPRINGER Journal of Modern Power Systems and Clean Energy, vol.4, no.1, pp.1-9, Jan. 2016.

[14] Vítor Monteiro, Andrés A. Nogueiras Meléndez, João L. Afonso, "Novel Single-Phase Five-Level VIENNA-Type Rectifier with Model Predictive Current Control,“ IEEE IECON Industrial Electronics Conference, pp.6413-6418, Nov. 2017.

[15] Marco Rivera, Venkata Yaramasu, Ana Llor, Jose Rodriguez, Bin Wu, Maurice Fadel, "Digital Predictive Current Control of a ThreePhase Four-Leg Inverter," IEEE Trans. Ind. Electron., vol.60, no.11, pp.4903-4912, Nov. 2013.

[16] Krishna Kumar Gupta, Alekh Ranjan, Pallavee Bhatnagar, Lalit Kumar Sahu, Shailendra Jain, "Multilevel Inverter Topologies With Reduced Device Count: A Review," IEEE Trans. Power Electron., vol.31, no.1, pp.135-151, Jan. 2016.

[17] A. Pandey, B. Singh, B. N. Singh, A. Chandra, K. Al-Haddad, D. P. Kothari, "A Review of Multilevel Power Converters," Journal of the Institution of Engineers, vol.8, pp.220-231, Mar.2006.

[18] Alireza Nami, Jiaqi Liang, Frans Dijkhuizen, Georgios D. Demetriades, "Modular Multilevel Converters for HVDC Applications: Review on Converter Cells and Functionalities," IEEE Trans. Power Electron., vol.30, no.1, pp.18-36, Jan. 2015.

[19] Suman Debnath, Jiangchao Qin, Behrooz Bahrani, Maryam Saeedifard, Peter Barbosa, "Operation, Control, and Applications of the Modular Multilevel Converter: A Review," IEEE Trans. Power Electron., vol.30, no.1, pp.37-53, Jan. 2015.

[20] Hani Vahedi, Philippe-Alexandre Labbé, Hadi Y. Kanaan, Handy Fortin Blanchette, Kamal Al-Haddad, "A New Five-Level BuckBoost Active Rectifier," IEEE ICIT International Conference on Industrial Technology, pp.2559-2564, Mar. 2015.

[21] Giampaolo Buticchi, Davide Barater, Emilio Lorenzani, Carlo Concari, Giovanni Franceschini, "A Nine-Level Grid-Connected Converter Topology for Single-Phase Transformerless PV Systems," IEEE Trans. Ind. Electron., vol.61, no.8, pp.3951-3960, Aug. 2014.

[22] Petar Grbovic, Alessandro Lidozzi, Luca Solero, Fabio Crescimbini, "Five-Level Unidirectional T-Rectifier for High Speed Gen-Set Applications," IEEE Trans. Ind. Appl., vol.52, no.2, pp.1642-1651, Mar. 2016.

[23] Vítor Monteiro, Andrés A. Nogueiras Meléndez, João C. Ferreira, Carlos Couto, João L. Afonso, "Experimental Validation of a Proposed Single-Phase Five-Level Active Rectifier Operating with Model Predictive Current Control,“ IEEE IECON Industrial Electronics Conference, pp.3939-3944, Nov. 2015.

[24] Carlos Alberto Teixeira, Donald Grahame Holmes, Brendan P. McGrath, "Single-Phase Semi-Bridge Five-Level Flying-Capacitor Rectifier," IEEE Trans. Ind. Appl., vol.49, no.5, pp.2158-2166, Sept. 2013.

[25] Liangzong He, Chen Cheng, "A Flying-Capacitor-Clamped FiveLevel Inverter Based on Bridge Modular Switched-Capacitor Topology," IEEE Trans. Ind. Electron., vol.63, no.2, pp.7814-7822, Dec. 2016.

[26] Bo Sun, Fengjiang Wu, Mehdi Savaghebi, Josep M. Guerrero, "A Flexible Five-level Cascaded H-bridge Inverter for Photovoltaic Gird-Connected Systems," IEEE ECCE International Conference on Power Electronics, Seoul Korea, pp.2369-2375, June 2015.

[27] João A. Ferreira Neto, Francisco J. B. Brito, Davi R. Joca, Marcos A. N. Nunes, René P. Torrico-Bascopé, "A Five-Level NPC Bidirectional Converter Based on Multistate Switching Cell Operating as Boost Rectifier," IEEE Brazilian Power Electronics Conference, Gramado Brazil, pp.79-84, Oct. 2013.

[28] Masoud Karimi-Ghartemani, "Linear and Pseudolinear Enhanced Phased-Locked Loop (EPLL) Structures," IEEE Trans. Ind. Electron., vol.61, no.3, pp.1464-1474, Mar. 2014. 